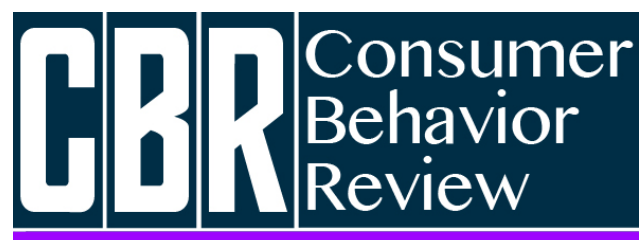

Revista Comportamento do Consumidor
Dantas, B. L. L., Pellizzoni, L. N., Bachmann, T. H. B., \& Abreu, N. R. (2020). Moda Livre! O comportamento de consumo diante de condições de trabalho alusivo ao escravo. Consumer Behavior Review, 4(3), 272-289.
ISSN: 2526-7884

Editor: Prof. Dr. Marconi Freitas da Costa Journal's e-mail: cbr@ufpe.br
Evaluation: Double blind review

Received: March 31, 2020

Accepted: August 22, 2020

\title{
MODA LIVRE! O COMPORTAMENTO DE CONSUMO DIANTE DE CONDIÇÕES DE TRABALHO ALUSIVO AO ESCRAVO
}

Free Fashion! Consumer behavior in the face of working conditions alluding to slavery

\author{
Bruna Lourena de Lima Dantas ${ }^{1}$ \\ ORCID: https://orcid.org/0000-0002-3935-5947 \\ E-mail: brunalimadantas.adm@gmail.com \\ Lívia Nogueira Pellizzoni ${ }^{2}$ \\ ORCID: https://orcid.org/0000-0001-6996-0702 \\ E-mail: livianogueira.adm@gmail.com \\ Thaisa Hasse Bogoni Bachmann ${ }^{3}$ \\ ORCID: https://orcid.org/0000-0003-3130-4560 \\ E-mail: thabogoni@gmail.com \\ Nelsio Rodrigues de $\mathrm{Abreu}^{1}$ \\ ORCID: https://orcid.org/0000-0001-7024-5642 \\ E-mail: nelsio@gmail.com

\begin{abstract}
${ }^{1}$ Universidade Federal da Paraíba, João Pessoa, Brasil
${ }^{2}$ Centro Universitário de João Pessoa, João Pessoa, Brasil

${ }^{3}$ Pontifícia Universidade Católica do Paraná, Curitiba, Brasil
\end{abstract}

\begin{abstract}
Resumo
0 presente artigo tem como objetivo compreender o comportamento de consumo diante de condições de trabalho alusivo ao escravo. Para tanto, foram realizados três grupos focais com mulheres, partindo de um roteiro semiestruturado, considerando as
\end{abstract}

\begin{abstract}
This article aims to identify consumers' perception of working conditions alluding to slavery and inclination to purchase. To this end, three focus groups were carried out with women, starting from a semi-structured script, considering the categories: meanings
\end{abstract}


categorias: significados de consumo de moda, percepção do consumidor a respeito das condições de trabalho nas indústrias têxteis e percepção do consumidor a respeito dos movimentos de moda consciente. A partir das análises, observou-se que as condições de trabalho nas indústrias têxteis não são consideradas critérios na decisão de compra por parte das consumidoras, uma vez que as participantes consideram que consumo consciente está relacionado à sustentabilidade dos materiais, diminuição do excedente de produção ou causas ambientais. Adicionalmente, observou-se que os consumidores não costumam buscar informações relativas às condições de trabalho do processo produtivo. Sugere-se, portanto, ações de comunicação para promover maior sensibilização.

Palavras-chave: Moda Livre; Consumo consciente; Inclinação à compra. of fashion consumption, consumer perception about working conditions in the textile industries and consumer perception about conscious fashion movements. From the analysis, it was observed that the working conditions in the textile industries are not considered criteria in the purchase decision by consumers, since the participants consider that conscious consumption is related to the sustainability of the materials, reduction of the production surplus or environmental causes. Additionally, it is concluded that the consumer has his share of responsibility when buying from companies involved with such cases and applications such as Moda Livre can help in his awareness.

Keywords: Free Fashion; Conscious consumption; Inclination to purchase

This work is licensed under a Creative Commons Attribution 4.0 International License.

\section{INTRODUÇÃO}

Consumir é um ato elementar e essencialmente baseado em escolhas. Muitas vezes pode ser considerado algo banal que permeia a rotina das pessoas. Por tratar-se de uma atividade do cotidiano, realizada para atender algumas necessidades para a sobrevivência biológica dos seres humanos, em diversas ocasiões ocorre sem ser planejado, pois não é considerado como algo a se despender muito tempo ou reflexão para a tomada de decisões (Bauman, 2008).

A capacidade de decisão de compra está intrinsecamente relacionada a uma série de fatores pertencentes a história de vida de cada pessoa, que vão desde sua origem, cultura, valores familiares, educação, formação profissional, e perpassam também outros elementos como relacionamentos, classe econômica, religião, ideais políticos, construção identitária e filiação social. Assim, o comportamento de consumo é também um fator relevante para a construção da estima perante grupos de interesse e mesmo quando aparenta ser algo supérfluo, na realidade pode ser considerado algo funcional, pois seja pela comodidade que proporciona, seja pela simbologia que representa, pode contribuir para a auto realização, proporcionar satisfação e ser um propulsor para o encontro da felicidade (Baudrillard, 1998).

As possibilidades de acesso à informação e consumo são cada vez maiores e a dinâmica de consumo atual promove o encontro de consumidores com uma infinidade de marcas e conveniências. De um lado, tal fato promove um sentimento de liberdade de escolha, prazer e pertencimento a grupos sociais específicos, mas de outro propicia uma cultura de consumo desenfreado ou impensado. As pessoas compram, mas não questionam suas reais necessidades, os motivos pelos quais estão consumindo ou a origem e descarte dos bens que adquirem, tampouco o processo de produção envolvido para a fabricação do bem (Razaaq et al. 2018).

A produção de moda possui uma cadeia industrial considerada uma das mais complexas e extensas da indústria da manufatura. Para converter a fibra têxtil bruta em tecido acabado e posteriormente no produto final para ser comercializado, é necessário a utilização de diversos recursos que incluem mão de obra, energia, água e outros que, quando acumulados, geram um setor de grande impacto (Fletcher, 2008).

Dessa forma, a indústria da moda por um lado é reconhecida como o segundo setor que mais consome água e polui, emitindo até $10 \%$ dos gases estufa do planeta, além de ser pautada por diversos 
abusos trabalhistas, como salários baixos, horas de trabalho excessivas e forçadas, falta de segurança no emprego e de direitos sindicais. Por outro lado, também traz benefícios, principalmente porque cria produtos que estão no centro de nossa cultura, geram riqueza e empregos. Avaliada em cerca de US\$ 2,5 trilhões e responsável por gerar mais de 60 milhões de empregos em todo o mundo, a indústria têxtil é um dos maiores motores econômicos do mundo, segundo dados da ONU Meio Ambiente. (Assembleia Ambiental da ONU mira soluções inovadoras para futuro global - ONU Brasil)

Mais especificamente no mercado da moda, objeto de estudo desta pesquisa, grandes problemas se relacionam ao seu processo produtivo, que entre outras etapas compreende: fiação, tecelagem, malharia, beneficiamento de tecidos, confecção e corresponde a uma fatia da economia que movimenta milhões de reais todos os anos. As consequências negativas que a produção desses bens pode acarretar gira em torno de problemas ambientais e problemas sociais (Cordeiro et al., 2013; Nunes, 2016) especialmente no que se refere às condições de trabalho que diversas empresas fornecem, muitas vezes consideradas análogas à escravidão (Close, 2014).

Neste sentido, o papel do consumidor passa a ser mais relevante, pois o seu comportamento de compra não afeta apenas a si mesmo ou ao ambiente, mas acarreta consequências que vão além dos significados imbricados nos bens e/ou serviços adquiridos (McNeill \& Snowdon, 2019). Um dos motivos relatados pelos consumidores, no que concerne à escolha de consumo e marcas que utilizam trabalho análogo à escravidão, é a falta de informação.

Para tanto, o aplicativo Moda Livre foi desenvolvido pela organização Repórter Brasil, que é reconhecida nacionalmente pelo trabalho que realiza no combate ao trabalho escravo e na promoção da defesa de direitos sociais e ambientais, atuando nas áreas de Jornalismo e Pesquisa e Metodologia Educacional. Assim, busca informar os consumidores sobre a reputação de diversas marcas a respeito de uma série de categorias que concluem sobre a transparência no processo produtivo de seus bens.

No que se refere às pesquisas acadêmicas acerca do processo produtivo das roupas, Razaaq et al. (2018) esboçam uma discussão a respeito do consumo de moda em relação à insustentabilidade, enquanto McNeill e Sownoldon (2019) discutem a respeito do movimento slow fashion e sua relação com a consciência no consumo. Dentro desse contexto, Clube e Tenant (2020) sugerem estratégias para minimizar os impactos insustentáveis da indústria fast fashion no meio ambiente.

Assim, após pesquisas nas principais bases de dados, com o propósito de identificar publicações que tratem da discussão de condições análogas à escravidão, foram realizadas buscas na base Scielo e na Ebsco, utilizando como recorte temporal de publicações entre 2015-2019. Na Scielo foi localizado apenas um artigo com as palavras-chave "bad labor conditions" e "labor analogous slaver" em Ciências Sociais Aplicadas. Na base de dados da Ebsco Host, foram localizados 734 artigos com as palavras-chave "bad labor conditions", sendo que apenas 3 foram localizadas com a associação da palavra "fashion". Ao utilizar as palavras "labor analogous slavery", foram localizados 70 artigos, sendo apenas 8 ligados a condições de trabalho na indústria e nenhum associado à palavra "fashion" ou "fashion industry". Encontrando-se então a lacuna teórica, que é contribuir com os estudos em comportamento do consumidor que analisem o consumo consciente diante de empresas que possuem condições de trabalho alusivo ao escravo em seu processo produtivo.

Diante do exposto, o objetivo da presente pesquisa é compreender o comportamento de consumo diante de condições de trabalho alusivo ao escravo. Para tanto, utiliza uma metodologia qualitativa, com aplicação de três grupos focais com mulheres residentes na cidade de João Pessoa/PB. Tal estudo tem sua relevância em contribuir na percepção do comportamento do consumidor quanto ao seu envolvimento social no ato do consumo, buscando perceber o seu conhecimento acerca do processo produtivo de roupas. Quanto às contribuições mercadológicas, o conhecimento acerca das percepções de consumidoras de moda, no que tange ao processo produtivo, pode auxiliar gestores a traçarem estratégias de marketing que evidenciem a transparência no seu processo produtivo e o seu comprometimento com causas ambientais e sociais.

0 artigo segue estruturado com a fundamentação teórica, que versa sobre consumo de moda, trabalho análogo ao escravo na produção de vestuário e moda consciente e sobre os movimentos de sensibilização. Na sequência, detalha os procedimentos metodológicos utilizados, a discussão dos resultados e por último, as considerações finais. 


\section{FUNDAMENTAÇÃO TEÓRICA \\ Consumo de moda}

$\mathrm{O}$ ato de consumir fornece aos seres humanos a capacidade de atender necessidades e desejos, expressar sua identidade e filiar-se em grupos sociais (McCracken, 2007; Lipovetsky, 2007; Bauman, 2008; Belk, 2013; Cordeiro et al., 2013). Dentro desse contexto, a moda surge como expressão artística das mudanças sociais a partir de seus criadores e como expressão da identidade de seus consumidores (Farias et al., 2019). McNeill e Moore (2015) explicam que as motivações para consumir moda estão centradas majoritariamente na expressão das identidades e que esses motivos são primordiais, considerando que a preocupação com o meio ambiente ou com questões éticas, no sentido de consumo sustentável ou consciente, não é uma prioridade para os consumidores desse tipo de produto, que compreende uma ampla gama quanto à sua variedade. É sabido também que o consumo de moda, principalmente fast fashion, pode ter motivações relacionadas à aceitação e filiação em grupos sociais, reforçando assim o consumo conspícuo (Dantas, 2018).

Assim, a moda possui diversas vertentes, que perpassam os itens de vestuário, mas para fins de investigação desse artigo, vamos nos ater a falar de moda restringindo às roupas. Quanto à vestuário, a moda se divide essencialmente entre os segmentos slow fashion e fast fashion. 0 primeiro dá conta de peças atemporais e duradouras, enquanto o segundo, despontado na década de 90, concomitantemente ao surgimento das lojas de departamento, atende a uma demanda de consumidores ansiosos por produtos que acompanhem uma tendência universal de maneira rápida, relativamente barata e pouco duradoura (Watson \& Yan, 2013).

Facilitado pela terceirização e inovações na cadeia de suprimentos, o fast fashion abarca o surgimento contínuo de tendências que se proliferam e são consumidas excessivamente (Jorgensen \& Jensen, 2012). A essência do fast fashion não está centrada na qualidade e durabilidade das roupas, e sim no acompanhamento das tendências, da flexibilidade e da resposta à demanda, já que o preço pode levar a um consumo de grandes quantidades dessas peças. 0 fast fashion então é mais do que um modelo de produção, é um novo modelo de negócios que movimenta, em grande escala, a economia de muitas empresas varejistas nacionais e internacionais (Cietta, 2012; Pookulangara \& Sheperd., 2013; McNeill \& Snowdon, 2019).

No tocante à economia, a produção de roupas a um baixo custo e consumo rápido implica numa cadeia produtiva têxtil cada vez mais complexa, que compreende: fiação, tecelagem, malharia, beneficiamento de tecidos, confecção, e corresponde a uma fatia da economia que movimenta milhões de reais todos os anos. No entanto, embora seja importante atentar para os aspectos ambientais e sociais que a fabricação dos produtos pode acarretar (Cordeiro et al. 2013; Nunes, 2016), não há devida preocupação com a sustentabilidade do meio ambiente. 0 modelo fast fashion está pautado na novidade e encontra respaldo para tal em suas consumidoras.

A respeito do surgimento do conceito de moda e do seu estabelecimento como sistema de consumo vigente, McCracken (2007) utiliza as discussões sobre cultura de consumo para explanar as lojas de departamento como as principais responsáveis para que o desejo de acompanhar as coleções fosse potencializado e popularizado entre as diversas camadas da população.

0 desejo de seguir as tendências de moda é pautado por uma insatisfação contínua (Bauman, 2008) de demanda praticamente inesgotável que alimenta o sistema e favorece o consumo e descarte rápido. Bauman (2011) explica o anseio por esse tipo de consumo como uma busca por significados e desejo de reprodução do estilo de vida recomendado pelas últimas ofertas do mercado e elogiado por porta-vozes contratados ou voluntários desse mesmo mercado. Dessa forma, põe em xeque a liberdade que os consumidores acreditam que possuem, mas que pode ser passível de questionamento mediante as fortes influências que recebem.

Consumir moda, portanto, significa investir na auto afiliação social. Embora muitas vezes seja um ato consciente, o consumo simbólico de produtos envolve a personalidade das pessoas e as representações de quem elas pretendem ser ou parecer, ou seja, a imitação ou expressão dos seus próprios estilos de vida (Lipovetsky, 2009; Bauman, 2008). 0 consumo de moda também representa a forma pela qual o espaço social é conhecido, explorado, comunicado e refletido, e representa um meio 
pelo qual as pessoas se expressam e a sociedade demonstra sua necessidade de mudanças (Lipovetsky, 2007).

\section{Trabalho análogo ao escravo na produção de vestuário}

Considerando a multiplicidade de fatores envolvidos na moda e sua relevância econômica, as empresas da indústria têxtil tendem a buscar soluções de produção de baixo custo que implicam muitas vezes na má remuneração da mão de obra e até em condições impróprias de trabalho, análogas à escravidão, em desacordo com a legislação vigente, como em países em desenvolvimento (Cairns \& Robertskim, 2007; Choo \& Yoon, 2013; Close, 2014). Para essas funções normalmente são eleitos candidatos em condições de desamparo e vulnerabilidade frente a seus direitos, especialmente imigrantes ilegais, mulheres e crianças.

No que tange à moda, o trabalho análogo à escravidão se dá em específico devido ao modelo de negócio que muitas empresas multinacionais adotaram. Roussenq (2017) explica que o modelo comandado por compradores tem como principal característica a projeção e/ou comercialização dos produtos, mas geralmente não são responsáveis diretos pelo processo de fabricação, gerando, assim, uma nova categoria de "fabricantes sem fábricas".

Na primeira convenção sobre escravidão realizada em 1926 pela Organização Internacional do Trabalho (OIT), o termo escravidão foi definido como "estado ou condição de um indivíduo sobre o qual exercem, total ou parcialmente, alguns ou todos os tributos do direito de propriedade" (Balduíno, 1999, p. 50). Nesse sentido, Neto (2008) considera que toda condição de exploração do indivíduo, na qual ele sofre coação para realizar atividades de qualquer natureza em condições degradantes e sem liberdade para modificar a situação, pode ser considerado um trabalho análogo à escravidão. Tal imposição não necessariamente deve ser física, podendo ser enquadrada também situações em que existe precariedade na higiene ou segurança do ambiente de trabalho, carga horária abusiva, maus tratos e violência, falta de assistência médica ou alimentação inadequada (Balduíno, 1999; Repórter Brasil, 2015).

De acordo com a legislação brasileira, configura trabalho escravo condições degradantes (que excluem o trabalhador de sua dignidade), jornada exaustiva (que impede o trabalhador de se recuperar fisicamente e ter vida social), trabalho forçado (manter o funcionário no serviço por meio de fraudes, isolamento geográfico, retenção de documentos, ameaças físicas e/ou psicológicas, violência) e servidão por dívida (fazer o trabalhador contrair ilegalmente uma dívida e prendê-lo a ela) (OIT, 1930).

No entanto, observa-se um crescente interesse por essa temática, elucidado principalmente por movimentos como o "Fashion Revolution", que se originou, segundo o site do movimento (https://www.fashionrevolution.org/south-america/brazil/), após o desabamento de uma indústria têxtil em Bangladesh que apresentava condições inadequadas de trabalho e, mesmo sob reivindicações dos funcionários, manteve-se inerte e obrigou os funcionários a continuarem trabalhando, o que resultou em 1.133 mortos e 2,5 mil feridos. Tal acontecimento ganhou ainda mais força com denúncias de condições inadequadas de trabalho, o que resultou na baixa de investimentos de acionistas nas empresas envolvidas e trouxe à tona essa discussão, principalmente relacionadas com a fast fashion, apresentadas no documentário "The True Cost" (2015) do diretor francês Andrew Morgan.

Apesar disso, o que ainda é alarmante é o quanto os consumidores muitas vezes têm uma atitude passiva por falta de conhecimento, ou por não se importarem sobre em que condições as roupas são feitas. Nesse sentido, Mahoney (2018) defende que as empresas devem ser mais criteriosas na busca por transparência quanto às condições de trabalho dos fornecedores e adotar políticas de transparência com o consumidor final, buscando implementar direitos humanos adequados por toda a cadeia de suprimentos. Uma vez que os fabricantes assumem o investimento na construção de relações estáveis entre comprador-fornecedor a longo prazo, consequentemente os fornecedores estarão mais inclinados a investir em melhorias de eficiência (Mahoney, 2018).

Uma das ações desenvolvidas nesse sentido pelo movimento Fashion Revolution foi o Fashion Transparency Index. Esse índice tem como objetivo classificar empresas da indústria da moda de acordo com o nível de transparência de sua cadeia de suprimentos (Revolution, 2016). Tal ação visa 
trazer ao consumidor uma reflexão acerca do quão pouco se sabe das empresas de moda, no sentido de encorajá-lo a uma decisão de compra mais consciente, que pode ter uma interferência direta em seu bem-estar (Nascimento, 2019) e, para os varejistas, desenvolver um meio de publicizar suas políticas e práticas.

Para a realização desse índice, o grupo utilizou cinco critérios de análise: política e comprometimento, rastreamento e rastreabilidade, auditorias e remediação, engajamento e colaboração e, por fim, governança. A partir desses critérios, o índice analisa o quanto as marcas sabem sobre suas cadeias de suprimentos, que tipo de políticas têm e quanto elas compartilham com o público suas práticas e produtos (Revolution, 2016).

No Brasil, desde 2010 a ONG Repórter Brasil identificou mais de 400 costureiros e costureiras em condições análogas à escravidão, sendo que sua maioria em confecções terceirizadas em São Paulo, envolvendo empresas famosas na exploração de trabalhadores, especialmente imigrantes bolivianos. Além disso, segundo o Global Slavery Index, de 2014, o Brasil está no 143o lugar do ranking de países com maior prevalência da escravidão moderna, liderado pela Mauritânia, Uzbequistão, Haiti e Índia.

Com o propósito semelhante ao do Fashion Revolution, a ONG Repórter Brasil desenvolveu um aplicativo chamado "Moda Livre" que apresenta uma lista de empresas que foram flagradas pelos fiscais do Ministério do Trabalho e Emprego em casos de trabalho escravo. Para o desenvolvimento dessa lista, as companhias foram convidadas a responder um questionário baseado em quatro indicadores (Quadro 1).

\begin{tabular}{|c|l|}
\hline INDICADOR & \multicolumn{1}{c|}{ DESCRIÇÃo } \\
\hline Políticas & $\begin{array}{l}\text { Compromissos assumidos pelas empresas para combater o trabalho escravo em } \\
\text { sua cadeia de fornecimento }\end{array}$ \\
\hline Monitoramento & Medidas adotadas para fiscalizar os fornecedores de roupa \\
\hline Transparência & $\begin{array}{l}\text { Ações tomadas para comunicar aos clientes o que tem sido feito para monitorar } \\
\text { fornecedores e combater o trabalho escravo }\end{array}$ \\
\hline Histórico & $\begin{array}{l}\text { Resumo do envolvimento das empresas em casos de trabalho escravo, segundo o } \\
\text { Ministério do Trabalho e Emprego (MTE), desde 24 de julho de 2009 - data do } \\
\text { lançamento do "Pacto Contra a Precarização e pelo Emprego e Trabalho } \\
\text { Decentes em São Paulo - Cadeia Produtiva das Confecções". }\end{array}$ \\
\hline
\end{tabular}

Fonte: Adaptado do app Moda Livre (2020).

Quadro 1: Indicadores de classificação das empresas em relação ao trabalho escravo.

A partir desses critérios, as empresas são classificadas em uma escala de cores, sendo verde as empresas que demonstram mecanismos de acompanhamento sobre sua cadeia produtiva e possuem histórico favorável em relação ao tema, amarelo as empresas que demonstram ter mecanismos de acompanhamento, mas possuem histórico desfavorável em casos de trabalho escravo e/ou precisam aprimorar mecanismos e, por fim, vermelho as empresas que não demonstram ter mecanismos de acompanhamento e têm histórico desfavorável em relação ao tema, ou não responderam ao questionário.

\section{Moda consciente e os movimentos de sensibilização}

O consumo de moda tem sido repensado por diversas pessoas que buscam um estilo de vida mais sustentável e mostram-se preocupadas com os impactos que seu comportamento pode causar para o bem da sociedade no presente e no futuro. De acordo com Lipovestky (2009), um ponto importante é a reinterpretação da era da futilidade no consumo e na comunicação, pois a moda pode ser considerada um agente supremo nos vários tipos de manifestações que as pessoas promovem num âmbito individualista.

No que tange ao movimento de sensibilização do mercado e de algumas empresas em específico, com relação à promoção do consumo consciente de moda e a preocupação com a 
idoneidade nas etapas da cadeia produtiva, podemos citar alguns movimentos encontrados em pesquisas realizadas em diferentes locais do mundo. Um deles trata-se de um estudo feito com três marcas de roupas suecas para avaliar a construção de silêncio sobre questões de sustentabilidade no discurso junto aos consumidores. Nesse estudo foi examinado até que ponto posicionar-se como uma marca eco-fashion pode atrair a atenção dos consumidores de forma positiva ou promover cobranças que vão além da sua capacidade e iniciativas por uma atuação mais sustentável. Dessa maneira, as roupas são projetadas e fabricadas para maximizar os benefícios para as pessoas e a sociedade, ao mesmo tempo em que minimiza os impactos ambientais adversos (Chan \& Wong, 2012; Solér, Baeza \& Svärd, 2015; Evans \& Peirson-Smith, 2018).

De acordo com Fletcher (2008), a indústria da moda é frequentemente relacionada ao emprego de pessoas e recursos de forma indevida e abusiva. Como implicação desta situação, nas últimas décadas surgiram então alguns movimentos contrários ao consumo desenfreado e aos impactos negativos causados por práticas insustentáveis promovidas no mercado da moda. Alguns autores apresentam então o conceito de moda consciente, moda sustentável ou ainda slow fashion dentro deste contexto, onde o processo é revisto como um todo, visando adequações tanto nas etapas de produção, quanto nas condições de trabalho, na preocupação com o meio ambiente e na sustentabilidade do negócio.

O termo "slow fashion" foi utilizado pela primeira vez em 2007 por Kate Fletcher, pesquisadora do Centro pela Moda Sustentável, localizado no Reino Unido. A origem está relacionada ao movimento do Slow Food, iniciado em 1986 por Carlo Petrini na Itália, e ao incentivo do consumo de alimentos cultivados de forma orgânica e produtos regionais. Assim, o conceito do Slow Fashion relaciona-se ao consumo de moda de forma consciente e sustentável (Watson \&Yan, 2013; Ertekin \& Atik, 2015).

Segundo Fletcher (2010), o slow fashion surgiu como um movimento que vai contra as atividades de crescimento obsessivo e compulsivo. Mais do que uma relação com a velocidade de consumo, o slow fashion caracteriza-se pela compra feita com coerência, onde a variedade e multiplicidade da cadeia produtiva são importantes, bem como encontra-se prazer no significado cultural da moda observando-se a importância de fatores como costumes, diversidade, qualidade e sustentabilidade, valorizando a sabedoria da experiência num âmbito mais completo. 0 conceito de slow fashion pode ser considerado um segmento de mercado, onde as marcas se posicionam valorizando seus produtos com características como uma herança de longa data, peças duráveis e design clássico, e como no argumento de Watson e Yan (2013), um modelo único, diferenciado.

A cultura do slow busca a democratização do fashion, mesmo quando associada a preços mais altos, pois permite às pessoas a possibilidade de controlar as instituições e tecnologias envolvidas, onde a compra é realizada com a consciência do que é necessário para o sustento da cadeia produtiva e quais recursos, ecossistemas e comunidades estão envolvidos na atuação das empresas do segmento de vestuário (Fletcher, 2010).

De acordo com Cline (2012), o processo de cocriação seria um diferencial no sistema de produção da moda slow fashion, pois os designers responsáveis por criar as coleções podem convidar os consumidores para participar do processo criativo, satisfazendo assim necessidades relacionadas à criatividade e identidade (Zanette et al., 2013). Outro fator positivo que o autor aponta na prática dos consumidores é a reutilização de roupas, que podem ser customizadas, recicladas, revendidas ou doadas, o que reduz o impacto das roupas no meio ambiente e na sociedade, com a economia dos recursos naturais e a diminuição de desperdício e energia.

Apesar de ser uma área de estudos relativamente nova, algumas pesquisas já apresentam perfis de consumidores de acordo com a perspectiva do comportamento de compra focado no conceito do slow fashion. Em seus estudos, buscando contribuir com a definição do termo, Jung e Jin (2014) propuseram cinco subdimensões do slow fashion, usando o paradigma de desenvolvimento de escala de Churchill (1979), com o objetivo de medir as intenções de compra dos consumidores. As cinco dimensões são compostas por Equidade, Autenticidade, Funcionalidade, Localismo e Exclusividade.

Para avaliar o comportamento dos consumidores usando estas 5 dimensões, foram identificados os perfis de 4 grupos diferentes, que foram denominados como: (1) grupo das pessoas altamente envolvidas em slow fashion; (2) grupo convencional; (3) grupo orientado pela exclusividade; e (4) grupo com baixo envolvimento em slow fashion. 0 estudo permitiu uma compreensão inicial dos 
motivos que levam as pessoas a consumirem a moda slow fashion e deu início a uma valiosa análise que sugeriu como continuação o desenvolvimento de programas com foco na educação do consumidor e criação de políticas governamentais frente à necessidade de hábitos de consumo mais sustentáveis por parte da sociedade.

Dentre os movimentos de sensibilização é possível citar também uma pesquisa desenvolvida por McNeill e Moore (2015), que aplicou o modelo de teoria do desenvolvimento, contextualizado para o segmento de moda, encontrando como resultado a possibilidade de classificar os consumidores em três tipos de grupos, denominados: (1) 'Self' consumidores, que são aqueles que possuem necessidades hedonísticas; (2) consumidores sociais, que são aqueles que se preocupam com uma imagem social; e os (3) consumidores que se sacrificam, que são aqueles que buscam reduzir os impactos negativos do seu comportamento no mundo. A pesquisa buscou entender como estes grupos percebem o consumo do fast fashion, e, consequentemente, como a atuação de marcas engajadas com a sustentabilidade em seu processo produtivo possuem apelos e oportunidades de negociação consideravelmente diferentes entre eles.

Na perspectiva de compreender como o comportamento de consumo pode ser percebido como algo individual ou coletivo, De Menezes (2018) descreve que existem pessoas que possuem consciência mais voltada ao coletivo, e que buscam um equilíbrio entre satisfazer suas necessidades imediatas e medir as consequências que seus atos podem trazer ao bem-estar dos outros e à natureza, seja a curto, médio ou longo prazos. Assim, o Desenvolvimento Sustentável pode ser estruturado com base em três pilares: as necessidades humanas, a preservação do meio ambiente e a orientação individualista-coletivista. Quanto mais orientada para o grupo, consequentemente a pessoa estará mais propensa a valorizar o desenvolvimento sustentável e preocupada em saber se as etapas do processo de produção acontecem de maneira eticamente responsável.

Para o presente estudo, os trabalhos apresentados neste capítulo demonstram abordagens e visões que corroboram com a importância da discussão do tema e da análise de como os indivíduos percebem seus atos de consumo como algo que se relaciona ao desenvolvimento da sociedade, pois pode ter consequências positivas ou negativas no âmbito coletivo e não apenas no individual.

\section{PROCEDIMENTOS METODOLÓGICOS}

0 estudo buscou através de uma pesquisa qualitativa identificar as percepções da consciência de consumidoras de moda e suas atitudes de consumo ou não, levando em consideração as potencialidades de trabalho análogo à escravidão no processo produtivo no setor de vestuário. Para tanto, foram realizados três grupos focais presenciais, visto que em um grupo focal é possível observar a interação em tempo real e as interações entre os membros (Morgan, 1996; Papaoikonomou \& Alarcón, 2017), além da oportunidade do participante buscar apoio de outros membros do grupo para dar suporte às suas opiniões, bem como do participante ouvir diversos pontos de vista sobre o tema e formar sua opinião (Abreu, Baldanza \& Gondim, 2009), o que deixa o coleta de dados com maior riqueza, que foi justamente o que aconteceu nos três grupos.

\begin{tabular}{|c|c|c|c|c|c|c|c|}
\hline G.F. & P. & Função & F.E. & E.C. & Escolaridade & R.F. (R\$) & D.G.F. \\
\hline \multirow{2}{*}{1} & P1 & Aposentada/estudante & $\begin{array}{c}+51 \\
\text { anos }\end{array}$ & Casada & $\begin{array}{c}\text { Superior Inc. } \\
\text { (cursando) }\end{array}$ & $\begin{array}{c}3.152,01 \mathrm{a} \\
7.880,00\end{array}$ & \\
\cline { 2 - 7 } & P2 & Cabeleireira & $\begin{array}{c}22 \text { a } 30 \\
\text { anos }\end{array}$ & Casada & $\begin{array}{c}\text { Superior Inc. } \\
\text { (cursando) }\end{array}$ & $\begin{array}{c}1.576,01 \mathrm{a} \\
3.152,00\end{array}$ & \multirow{2}{*}{ 1h3m30s } \\
\cline { 2 - 7 } & P3 & $\begin{array}{c}\text { Jovem Aprendiz } \\
\text { Bancária }\end{array}$ & $\begin{array}{c}18 \text { a } 21 \\
\text { anos }\end{array}$ & Solteira & $\begin{array}{c}\text { Superior Inc. } \\
\text { (cursando) }\end{array}$ & $\begin{array}{c}1.576,01 \mathrm{a} \\
3.152,00\end{array}$ & \\
\cline { 2 - 6 } & P4 & Estudante & $\begin{array}{c}22 \text { a } 30 \\
\text { anos }\end{array}$ & Solteira & $\begin{array}{c}\text { Superior Inc. } \\
\text { (cursando) }\end{array}$ & $\begin{array}{c}7.880,01 \mathrm{a} \\
15.760,00\end{array}$ & \\
\hline
\end{tabular}




\begin{tabular}{|c|c|c|c|c|c|c|c|}
\hline \multirow{8}{*}{2} & P5 & Estudante/Empresária & $\begin{array}{c}22 \text { a } 30 \\
\text { anos }\end{array}$ & Solteira & $\begin{array}{l}\text { Superior Inc. } \\
\text { (cursando) }\end{array}$ & $\begin{array}{l}7.880,01 \mathrm{a} \\
15.760,00\end{array}$ & \multirow{8}{*}{$1 \mathrm{~h} 06 \mathrm{~m}$} \\
\hline & P6 & Estudante & $\begin{array}{c}22 \text { a } 30 \\
\text { anos }\end{array}$ & Solteira & $\begin{array}{l}\text { Superior Inc. } \\
\text { (cursando) }\end{array}$ & $\begin{array}{l}998,01 \mathrm{a} \\
1.576,00\end{array}$ & \\
\hline & P7 & Estagiária & $\begin{array}{c}18 \text { a } 21 \\
\text { anos }\end{array}$ & Solteira & $\begin{array}{l}\text { Superior Inc. } \\
\text { (cursando) }\end{array}$ & $\begin{array}{c}1.576,01 \mathrm{a} \\
3.152,00\end{array}$ & \\
\hline & P8 & $\begin{array}{c}\text { Assistente } \\
\text { Administrativa }\end{array}$ & $\begin{array}{c}22 \text { a } 30 \\
\text { anos }\end{array}$ & Solteira & $\begin{array}{l}\text { Superior } \\
\text { Completo }\end{array}$ & $\begin{array}{c}1.576,01 \mathrm{a} \\
3.152,00\end{array}$ & \\
\hline & P9 & Estagiária & $\begin{array}{c}22 \text { a } 30 \\
\text { anos }\end{array}$ & Solteira & $\begin{array}{l}\text { Superior Inc. } \\
\text { (cursando) }\end{array}$ & $\begin{array}{l}998,01 \mathrm{a} \\
1.576,00\end{array}$ & \\
\hline & P10 & Autônoma & $\begin{array}{c}22 \text { a } 30 \\
\text { anos }\end{array}$ & Solteira & $\begin{array}{l}\text { Superior Inc. } \\
\text { (cursando) }\end{array}$ & $\begin{array}{l}998,01 \mathrm{a} \\
1.576,00\end{array}$ & \\
\hline & P11 & Estudante/Bancária & $\begin{array}{c}22 \text { a } 30 \\
\text { anos }\end{array}$ & Solteira & $\begin{array}{l}\text { Superior Inc. } \\
\text { (cursando) }\end{array}$ & $\begin{array}{l}7.880,01 \mathrm{a} \\
15.760,00\end{array}$ & \\
\hline & P12 & $\begin{array}{c}\text { Assistente } \\
\text { Administrativa }\end{array}$ & $\begin{array}{c}22 \text { a } 30 \\
\text { anos }\end{array}$ & Solteira & $\begin{array}{l}\text { Superior Inc. } \\
\text { (cursando) }\end{array}$ & $\begin{array}{c}1.576,01 \mathrm{a} \\
3.152,00\end{array}$ & \\
\hline \multirow{6}{*}{3} & P13 & $\begin{array}{l}\text { Coord. Assessoria de } \\
\text { Imprensa }\end{array}$ & $\begin{array}{c}31 \text { a } 40 \\
\text { anos }\end{array}$ & Solteira & $\begin{array}{l}\text { Superior Inc. } \\
\text { (cursando) }\end{array}$ & $\begin{array}{c}1.576,01 \mathrm{a} \\
3.152,00\end{array}$ & \multirow{6}{*}{$37 \mathrm{~m} 28 \mathrm{~s}$} \\
\hline & P14 & $\begin{array}{c}\text { Designer } \\
\text { Gráfico/Diretora de } \\
\text { Arte }\end{array}$ & $\begin{array}{c}22 \text { a } 30 \\
\text { anos }\end{array}$ & Solteira & $\begin{array}{l}\text { Superior } \\
\text { Completo }\end{array}$ & $\begin{array}{c}1.576,01 \mathrm{a} \\
3.152,00\end{array}$ & \\
\hline & P15 & Diretora de Operações & $\begin{array}{c}31 \text { a } 40 \\
\text { anos }\end{array}$ & Casada & $\begin{array}{l}\text { Superior } \\
\text { Completo }\end{array}$ & $\begin{array}{c}3.152,01 \mathrm{a} \\
7.880,00\end{array}$ & \\
\hline & P16 & $\begin{array}{l}\text { Estagiária/Social } \\
\text { Media }\end{array}$ & $\begin{array}{c}22 \text { a } 30 \\
\text { anos }\end{array}$ & Solteira & $\begin{array}{l}\text { Superior Inc. } \\
\text { (cursando) }\end{array}$ & $\begin{array}{c}1.576,01 \mathrm{a} \\
3.152,00\end{array}$ & \\
\hline & $\mathrm{P} 17$ & Diretora de Arte & $\begin{array}{c}22 \text { a } 30 \\
\text { anos }\end{array}$ & $\begin{array}{l}\text { União } \\
\text { Estável }\end{array}$ & $\begin{array}{l}\text { Superior inc. } \\
\text { (cursando) }\end{array}$ & $\begin{array}{c}1.576,01 \mathrm{a} \\
3.152,00\end{array}$ & \\
\hline & P18 & Atendimento & $\begin{array}{c}22 \text { a } 30 \\
\text { anos }\end{array}$ & Solteira & $\begin{array}{l}\text { Superior } \\
\text { Completo }\end{array}$ & $\begin{array}{l}7.880,01 \mathrm{a} \\
15.760,00\end{array}$ & \\
\hline
\end{tabular}

FONTE: Dados da pesquisa (2019). Legenda: G.F.: Número do Grupo Focal; P.: Participantes; Função.: Cargo/Função; F.E.: Faixa Etária; E.C.: Estado Civil; R.F.: Renda Familiar em Reais; D.G.F.: Duração do Grupo Focal.

Quadro 2: Perfil das participantes.

O contato inicial com as participantes se deu a partir da escolha de mulheres que preocupamse em comprar roupas da moda, pediu-se indicações a essas e assim, chegou-se às demais participantes, ou seja, através da técnica "bola de neve", que é o processo de indicação de outros sujeitos interessantes para a pesquisa, além de algumas conhecidas dos pesquisadores e a indicação das próprias participantes do estudo. Assim, foram realizados três grupos focais, totalizando 18 consumidoras com idades variando de 18 a 55 anos, com profissões e rendas familiares diversas, cursando ensino superior ou formadas, conforme pode ser visualizado no quadro 2 .

Os grupos focais foram realizados no mês de junho de 2019, em local de maior conveniência para as participantes, sendo dois grupos em duas universidades e um em escritório empresarial. E para as discussões nos grupos focais foi construído um roteiro semiestruturado com questões que 
foram ampliadas conforme o andamento das falas das participantes durante a realização dos grupos focais, processo normal e esperado em se tratando do uso de grupos focais tanto presenciais como online.

Deste modo, o instrumento foi elaborado baseado na teoria, a partir de um processo de abstração e discussão entre os autores do que foi lido, abordando os pontos centrais, tais como: Significados de consumo de moda, para que fosse possível entender o que a moda representa para as consumidoras, baseado em autores como McCracken (2007) e Lipovetsky (2009) e Bauman (2008); Percepção do consumidor a respeito das condições de trabalho nas indústrias têxteis, que foi fundamental para alcançar o objetivo e entender como as consumidoras percebem o processo produtivo das empresas de moda, baseado em Mahoney (2018) e Nascimento (2019); e Percepção do consumidor a respeito dos movimentos de moda consciente a fim de compreender o conhecimento das consumidoras acerca dos movimentos de consumo consciente, baseado especialmente em McNeill e Moore (2015) e Evans e Peirson-Smith (2018).

Assim, emergiram questões, como por exemplo: Para você, o que é ser um consumidor consciente?; Você se considera um consumidor consciente? Por que?; Você procura informações a respeito do processo produtivo das suas marcas preferidas? Caso afirmativo: como?; Você deixaria de comprar roupas de empresas que você consome atualmente, caso descobrisse que elas envolvem trabalho escravo na produção?, entre outras questões. Além disso, foi apresentado e demonstrado o uso do aplicativo MODA LIVRE, e deste modo, obteve-se informações mais detalhadas do envolvimento das participantes no processo de compra presente e futura de vestuários.

Para a realização dos grupos focais foram apresentados os objetivos do estudo, bem como o TCLE - Termo de Consentimento Livre e Esclarecido, assim todas as participantes leram, assinaram, ficaram com uma cópia e autorizam a participação no grupo focal e a gravação. Dessa forma, foram realizadas os grupos, estando sempre presente uma pesquisadora e um mediador qualificado (Morgan, 2009). E após o término das realizações dos grupos e as falas usadas ipsis litteris. 0 primeiro grupo teve a duração de uma hora e três minutos, o segundo grupo durou uma hora e seis minutos, enquanto o terceiro grupo teve duração de trinta e sete minutos.

Para análise dos dados utilizou-se a técnica de Análise do Discurso. Orlandi, (2009) conceitua o discurso como a palavra em ação ou a prática de linguagem. Assim, a análise se constitui em investigar como essas práticas atuam no presente, mantendo e promovendo as relações (Schiavini \& Garrid, 2018). A análise de discurso visa a compreensão dos sentidos que um objeto produz (Orlandini, 2009) portanto permite realizar uma interpretação focada na posição discursiva do sujeito, legitimada pela junção da vivência em sociedade e das experiências individuais (Caregnato \& Mutti, 2006). A pesquisa qualitativa, que permite atribuir cientificidade a conhecimentos teóricos empíricos, têm a preocupação de compreender os fenômenos a partir da perspectiva dos sujeitos, propondo reflexões sobre as experiências dos mesmos (Merriam, 2009).

Destarte, a análise de discurso permite a linguagem como mediação oportuna entre o homem e a realidade natural e social vivenciada. Iñiguez (2004) corrobora, destacando que o conhecimento e aprendizado, que é compartilhado socialmente entre os atores sociais, é o denominador habitual para a ação, a interação, o discurso e as práticas sociais.

0 material colhido foi organizado para identificar as partes que continham padrões relevantes que pudessem contribuir com a investigação, essa foi a primeira etapa do processo de análise proposto por Lüdke e André (1986). Em seguida foram realizadas análises e inferências das informações, a partir da relação entre as falas e experiências relatadas confrontadas com a leitura transcorrida ao longo do processo de elaboração da pesquisa, que foi a segunda etapa da análise, concordando Mano (2014). 0 objetivo nesta pesquisa foi aproximar-se do ideal de uma análise de discurso, entendendo as significações oferecidas pelas falas das respondentes dos grupos focais quanto às suas experiências de consumo de moda e suas nuances, numa relação entre linguagem, pensamento e mundo. 


\section{ANÁLISE DOS RESULTADOS \\ Significados de consumo de moda}

No Grupo 1 os critérios levantados pelas respondentes em relação aos parâmetros de escolha de roupas estavam relacionados à versatilidade da roupa em relação às várias possibilidades de uso e qualidade do tipo de tecido utilizado na confecção da mesma. Adicionalmente, a P3 levantou a importância do caimento da roupa, considerando a dificuldade de encontrar bons caimentos no tamanho plus size, sendo também importante para a mesma que as roupas tenham preços acessíveis. 0 segmento fast fashion consegue atender às exigências das consumidoras que preferem pagar pouco por vestuário, independente dos fatores e problemas envolvidos em seu modelo de negócio (Jorgensen \& Jensen, 2012).

No Grupo 2 o custo benefício foi citado por boa parte das respondentes como primordial e elementos como conforto e tendências de moda, qualidade e preço também foram mencionados. Elas mencionaram que costumam investir um valor mais alto em roupas que precisam utilizar na rotina e que precisam ter uma durabilidade maior, enquanto optam por pagar mais barato em roupas que seguem tendências de moda e costumam ser descartadas com maior facilidade. De acordo com Watson (2013), o fast fashion utiliza-se de minicoleções para incentivar a obsolescência programada da moda, causando um consumo desenfreado, que exige um processo produtivo de baixo custo. A P6 explicou que observa a qualidade da roupa no momento da compra e avalia o quanto vai usar aquela peça de roupa antes de investir um valor alto.

Com relação ao Grupo 3, as respondentes citaram preço, estilo e modelagem, a P17 relata que sempre foi uma pessoa bastante consumista, mas hoje adota um estilo de vida vegano e repensa suas compras, olhando primeiro o que precisa comprar, "eu tenho muita roupa, eu posso passar um mês sem lavar e ainda assim teria roupa [...] hoje eu avalio de onde vem a roupa, se eu posso reutilizar". A P13 explica que repensa as necessidades de suas roupas (McNeill \& Moore, 2015) e procura não acumular, promovendo bazares para se desfazer de parte delas. Observa-se então uma preocupação com o consumo racional, no entanto, nenhuma das respondentes de ambos os grupos considerou o processo produtivo ou o posicionamento sustentável da marca como critério de escolha na hora da compra. Explicam que os consumidores de moda se veem numa dualidade entre consumir produtos a um preço acessível que estão à sua disposição e seguir padrões ambientais e éticos de sustentabilidade.

Quanto ao que pensam em relação a ser um consumidor consciente, a P2 explica que está relacionado a planejar as compras para evitar a compra por impulso. A P4 corrobora com o pensamento, afirmando que está relacionado a comprar a quantidade adequada pelo preço adequado. A P3 fala de identificar a necessidade real antes de fazer a compra e acrescenta que, em determinadas situações, alugar uma roupa é uma atitude mais consciente e econômica. Já a P1 diz que alugar peças de roupa pode sair mais caro do que comprar, portanto prefere comprar peças que possam ser utilizadas em diversas ocasiões e, caso decida, revende, troca ou empresta a mesma peça. Para ela, "embora não movimente muito a economia, essas ações são mais conscientes". A esse respeito, a P3 levanta a questão de que tais práticas estão relacionadas ao biotipo da pessoa:

mas depende muito do padrão de corpo da pessoa. Por exemplo, uma pessoa que é mais magra ela é bem mais fácil de trocar roupa de conseguir comprar roupa em promoção. Já uma pessoa que é mais cheinha, já tem vários outros leques que vai ter que se preocupar. Por exemplo, uma roupa que dê em mim não vai dar em qualquer pessoa. (P3)

Adicionalmente, a P3 considera que a dificuldade de peças que caibam em pessoas que vestem plus size influenciam o consumo impulsivo, pois quando acha uma peça com bom caimento, compram diversas peças iguais. Nesse contexto, Zanette et al. (2013) colocam em evidência a importância do varejo na construção identitária de consumidoras plus size e as problemáticas que o modelo de negócio traz para essas consumidoras. Entre outras variáveis, a respondente P2 concorda que alugar 
nem sempre é a solução mais economicamente viável. P3 complementa que outra opção acessível é mandar fazer a peça na costureira.

A percepção sobre o que é ser um consumidor consciente no Grupo 2 levantou questões mais abrangentes, para além das escolhas das peças, mas também se referindo ao descarte. A esse respeito a P12 menciona: "Ser consciente é sempre prestar atenção do porquê tá comprando, quando você vai comprar, até quando você pode utilizar, como você vai descartar" a P7 concorda que é preciso avaliar se o artigo que será comprado é realmente necessário e utilizar aquilo que já se possui de maneira favorável, compreendendo que os recursos naturais do planeta são limitados, sobre esse assunto ela continua "é preciso fazer um autoexame. 0 que se passa na sua cabeça na hora de acreditar que você necessita comprar aquela roupa?!" levantando a discussão sobre os significados do consumo. A perspectiva de insaciabilidade explicada por Bauman (2008), onde o autor questiona se os consumidores realmente são livres para fazer suas escolhas, provoca a reflexão sobre o baixo nível de pensamento crítico e fortes influências para o consumo sob as quais estão sujeitas as consumidoras de moda.

As respondentes do Grupo 3 percebem o consumo consciente sob algumas vertentes. Para a P14 consumidor consciente é aquele que compra o que pode pagar. Já a P15 explica que existem vários critérios, como necessidade, analisar se aquele produto é testado em animais ou se advém de trabalho escravo. Essa foi a primeira vez que uma respondente mencionou o trabalho escravo voluntariamente associado ao consumo consciente.

As respondentes foram indagadas sobre o que seria consumo consciente para elas, e no geral seguiram uma linha de raciocínio próxima do que é conceituado na teoria. Quando indagadas sobre considerarem-se ou não consumidoras conscientes, P4 se considera consciente pela perspectiva de comprar pouco e selecionar bem antes de realizar a compra, embora reconheça que esse posicionamento se dê pela limitação financeira, pois "eu queria tanto, mais não posso, você vai nas redes sociais então o marketing nas lojas é direto, né, só colocando isso o tempo todo."

No Grupo 2 boa parte das respondentes se considera "mais ou menos consciente", a P7 se considera consciente pois não compra tudo o que deseja, mas avalia se precisa comprar, enquanto a R12 se considera consciente pois dá preferência a comprar roupas feitas por costureiras locais ou roupas oriundas de bazar, o que coloca em evidência que o movimento slow fashion pode ter um maior número de adeptos se utilizar de estratégias como a comunicação do valor que as peças possuem (McNeill \& Snowdon, 2019).

Destarte, por sua vez, a P5 falou que se considera uma consumidora parcialmente consciente, pois compra roupa sempre que passa em frente a uma loja, prova e a roupa veste bem, mesmo que não haja uma ocasião específica para utilizá-la. Por outro lado, procura utilizar ao máximo as roupas que possui, utilizando diferentes combinações. Essa respondente explicou que utiliza o Instagram para conferir as peças de roupas das lojas, e esse é o seu principal canal de compras, em seguida outras respondentes concordaram com ela. Adicionalmente, a P10 mencionou que não se considera uma consumidora plenamente consciente pois, apesar de também dar preferência para roupas feitas por costureiras locais, ela consome roupas das quais não conhece a origem e o processo produtivo. Aqui houve menção ao trabalho escravo.

No que se refere ao terceiro grupo, a P15 explica que hoje se considera uma consumidora consciente porque possui critérios de compra, que antes não possuía, como por exemplo a preocupação com o valor da marca, enquanto a P14 relata: "Eu ainda não pratico (consumo consciente), mas hoje tenho a consciência de que é possível comprar com alguns critérios".

\section{Percepção do consumidor a respeito das condições de trabalho nas indústrias têxteis}

Quanto a buscar informações das empresas antes de realizar uma compra, P3 diz que não busca informações e enfatiza que "o brasileiro não pensa nessas coisas". Já a P2, relatou que uma vez foi em uma loja na Alemanha e ficou surpresa com o preço baixo dos produtos. A partir disso começou a pensar mais na questão da mão-de-obra. No entanto, apesar de saber das condições de trabalho no Brasil, que de acordo com a legislação brasileira configura trabalho escravo (OIT, 1930), esse não é um dos critérios de pesquisa na hora da compra: 
sei que a mão de obra é um pouco explorada, em relação a salário, [...] exploram esse pessoal que vem do Uruguai, Paraguai, né?!, que eles colocam eles numas salas fechadas quentes, sem ventilação, inclusive quando houve um assassinato acho que até de uma criança, dentro de uma fábrica dessa, foi que descobriram que lá eles exploravam muito esse pessoal. (P2)

A respondente P1 diz que não pesquisa essas questões, que seu critério de pesquisa é em relação a qualidade do tecido por influência da sogra que é costureira. Acrescenta ainda que já comprou de empresas envolvidas em escândalos, mesmo tendo conhecimento de tais escândalos e que no momento ainda não tem, mas que deseja ter essa consciência na hora da escolha dos produtos.

A P7 explicou que tem uma amiga lojista e conferindo os preços muito baixos das roupas que ela compra em lojas advindas de São Paulo, concluiu que a procedência dos produtos pode ser duvidosa, por não ter condições de que fossem produzidas em condições corretas com aquele valor. Ela relatou que já realizou pesquisas e conferiu que em algumas regiões da Paraíba e Pernambuco existe produção de roupas em condições análogas à escravidão, no entanto, explica que esse tipo de informação dificilmente seria acessível a todas as pessoas e que ela teve acesso por ter colegas lojistas que entendem do processo produtivo das roupas.

A participante P11 relatou que sua mãe é costureira, por isso ela conhece o processo de produção, explicando que mesmo depois de cinco anos de trabalho, ela continuava a receber o mesmo valor pelas peças costuradas, enquanto a $\mathrm{P} 9$, que também possui mãe costureira relata:

[...] o valor recebido pelas peças é muito baixo, de fato a questão de ter que trabalhar muito em um curto espaço de tempo, agora assim, a minha mãe tinha a opção de trabalhar ou não porque ela trabalhava em casa, muitas pessoas não têm essa expectativa, realmente as condições de trabalho em alguns lugares não são boas, isso é o que eu conheço. (P9)

A P4 fala de lojas que sinalizam que o produto é sustentável e isso agrega valor. Reitera que apesar dos escândalos envolvendo empresas em relação às condições de trabalho, as pessoas não se importam, independente da nacionalidade. As participantes do Grupo 2 relataram que conhecem marcas de cosméticos veganas e que anunciam que são sustentáveis, mas não conhecem empresas de roupas que sigam a linha de consumo sustentável. A maioria das respondentes do Grupo 3 relata que não procura saber sobre o processo produtivo das roupas, e explica que pesquisa com pouca frequência:

Eu evito estar pesquisando sempre, porque no fim das contas, se a gente for muito criteriosa com relação a isso talvez a gente se frustre bastante [...] eu olho a etiqueta (da Adidas) e vejo que aquele produto foi feito no Vietnã, então eu vou pensar como é que aquelas pessoas estão trabalhando lá, então nesse caso eu evito porque gosto muito da marca, já tem outras marcas que eu pesquiso primeiro, então depende muito. (P15)

Ainda no Grupo 3, a respondente P18 relata a dificuldade que é conseguir ter uma percepção real das condições de trabalho nas indústrias têxteis, que mesmo ouvindo notícias no rádio ou na televisão, é improvável que essas condições sejam reveladas. Isso se deve, em boa parte, à dinâmica de produção e exposição adotada pelas empresas, mesmo aquelas que fabricam seus produtos dentro das condições legais, elas não costumam falar sobre o seu processo produtivo, nem incluir o seu cliente nesta etapa de desenvolvimento (Cline, 2012). 
Mesmo com a unanimidade de que apesar de não concordar com as condições de trabalho, os escândalos não influenciam na decisão de compra, todas as entrevistadas concordaram com a necessidade de melhores condições de trabalho, sem jornada exaustiva, com ambiente adequado que não ocasione danos à saúde (P3 e P4), ambiente ergonômico (P1), melhores condições de temperatura e rotatividade dos funcionários (P2).

Em relação à opinião das respondentes quanto ao fato de que, ao comprar de empresas com condições de trabalho análogas ao trabalho escravo, também estão financiando esse tipo de prática, as respondentes concordaram que sim. A P1 disse que justamente por isso essa consciência deve ser mais divulgada e a P3 fala que as empresas devem fazer campanhas e incentivar a venda consciente. Quase todas as outras participantes de todos os grupos concordam que comprar dessas empresas alimenta a cadeia de trabalho escravo.

Quando arguidas se deixariam de comprar roupas das empresas que consomem costumeiramente caso descobrissem que elas envolvem trabalho escravo na produção, as respondentes P1 e P3 afirmaram que deixariam apenas na condição de conseguir outras opções de produtos com a mesma qualidade e preço. P1 ainda menciona que existem muitos interesses envolvidos na fiscalização, por esse motivo a idoneidade nas empresas é relativa. A participante P8 explica: "existe uma empresa que eu gosto, a Zara, apesar de não ter aqui, sempre que eu viajo dou uma passada, eu sei que ela é envolvida em escândalos, na verdade acho que a maioria é, e se a gente for parar pra pensar nisso a gente acaba não comprando de nenhuma". O nome da mesma empresa surgiu na discussão do Grupo 3, a P14 relatou que costuma comprar na Zara, mesmo mediante escândalos envolvendo trabalho escravo. A referida empresa já foi discutida em estudos de Barnes e Lea-Greenwood (2010) e Kim, Choo e Yoon (2013), que abordavam as práticas consideradas indesejadas.

Adicionalmente, a P12 relatou achar que deixar de comprar das marcas envolvidas em escândalos não é a solução, é assumir uma postura social, mas não é ir na origem do problema, a P14 no Grupo 3 corrobora com essa opinião. Outras participantes relataram que deixariam de comprar de outras marcas caso houvesse a opção de comprar o mesmo produto em empresas que possuíssem boa reputação.

\section{Percepção do consumidor a respeito dos movimentos de moda consciente}

Em relação aos movimentos de consumo consciente e práticas sustentáveis, as participantes do Grupo 2 disseram não conhecer campanhas ou empresas que mostrem práticas conscientes, apenas uma participante disse conhecer uma marca de sapatos que trabalha com matéria-prima sustentável. Já no Grupo 3, uma participante citou o aplicativo Moda Livre, enquanto outra falou sobre a Body Shop, que no que concerne a consumo consciente, deixa claro que não faz testes dos seus produtos em animais. Nesse sentido, Razaaq (2018) explica que a atitude pró-ambiental de um indivíduo é formada como consequência de ter uma atitude positiva em relação a esse comportamento, ou seja, eles são sensíveis aos movimentos que se engajam em causas que se importam previamente.

As respondentes concordaram que um espaço para divulgação dessas informações, a exemplo do aplicativo Moda Livre, é um diferencial que pode apoiar o processo decisório. Para P1 e P2 esse tipo de iniciativa deve ser mais divulgado para facilitar práticas de consumo mais consciente, corroborando com Mahoney (2018) em relação a busca das empresas pela transparência em relação às condições de trabalho. Sobre o aplicativo em questão, as participantes do Grupo 2 concordam que ações como essa devem ser melhor divulgadas, para conhecimento geral da população. Para que o aplicativo tenha sucesso é necessário que o mesmo seja constantemente atualizado e também se pessoas com grande visibilidade na área de moda se engajarem na causa, há boas chances de haver um alcance maior.

A mudança no comportamento de consumo consciente de moda é explicado por Razaaq (2018) como influenciado por alguns fatores: inicialmente as consumidoras precisam acreditar que uma quantidade notável de pessoas já o pratica, ou seja, percebem regra social descritiva; segundo, precisam acreditar que deveria ser feito, isto é, regra social injuntiva percebida; e terceiro, ter uma crença consciente de que podem abraçar o novo comportamento, isto é, o controle comportamental 
percebido. Então, Pereira et al. (2017) explicam que as relações sociais são determinantes no que se refere a consumo consciente pró-ambiental.

Nas respostas das inquiridas observa-se o sentimento de que sozinhas elas não são capazes de alterar a realidade que está posta. Adicionalmente, a falta de informações por parte das empresas acerca do processo produtivo alimenta o estado de inércia acerca do engajamento em movimentos de consumo de moda consciente.

As participantes do Grupo 3 concordam que seria um diferencial para a marca investir em campanhas que demonstrem uma preocupação com o processo produtivo, engajadas numa produção consciente. Nesse sentido, fica evidente que a transparência do processo produtivo e um posicionamento estratégico no que concerne a evidenciar as boas condições de trabalho praticadas pode ser um diferencial competitivo a ser explorado pelas empresas do segmento de moda.

\section{Concepções de escolha de consumo}

Numa perspectiva de sobreposição das categorias, observou-se que as consumidoras em análise associam consumo consciente muito mais sob uma perspectiva financeira pessoal do que por aspectos relacionados ao bem estar da comunidade ou do meio ambiente. Dessa forma, pode-se considerar que, para elas, a moda como meio de auto expressão não abarca significados políticos, sociais e/ou ambientais. Mas apenas uma expressão do self, em consonância com Belk (2013), provavelmente pautada em influências culturais que preconizam estilo e tendências.

Por esse motivo as condições dos trabalhadores da indústria têxtil não aparecem como quesitos importantes no processo de escolha das mesmas. A exteriorização da co-responsabilidade ao comprar tais produtos advindos de condições alusivas ao trabalho escravo parece, portanto, ser justificada por questões de caimento, tamanho ou qualidade dos materiais, em detrimento de uma visão mais participativa do consumidor como ator nessas relações. Complementarmente, conforme Nascimento (2019) explana, as participantes não sentem que a sua atuação individual possa exercer uma influência direta no modelo de negócio das empresas envolvidas com trabalho escravo.

Apesar disso, a temática de certa forma sensibiliza as consumidoras ao ponto de concordarem com maior publicização dessas situações por meio de aplicativos ou outras mídias. Todavia, observase que esse interesse por maior divulgação das práticas de trabalho indevidas se embasa não necessariamente como oportunidade de tornar o consumidor mais consciente na exigência por trabalho justo, e sim no sentido de haver mais fiscalização e controle por parte de órgãos competentes. Isso não anula a importância da visão das respondentes, mas apresenta um contexto de terceirização de responsabilidade, uma vez que tanto quem produz como quem compra deveriam atuar conjuntamente por melhores práticas.

\section{CONSIDERAÇÕES FINAIS}

Apesar das diversas significações que o consumo de moda pode assumir no comportamento consumidor, a cadeia produtiva muitas vezes fica oculta dentre essas significações, impossibilitando uma análise mais ampla em relação ao papel social que o consumo pode representar. Nesse sentido, ao analisar o comportamento de consumo diante de condições de trabalho alusivo ao escravo, observouse que ainda há a necessidade de muito diálogo e disseminação de informações para que o consumidor assuma o papel de consumo consciente.

Embora as participantes desse estudo se sensibilizem com a temática, identificando causas ou consequências de condições degradantes nas produções têxteis e que mesmo assim, considerem que continuar comprando de tais empresas também representa estar financiando tais práticas, percebeuse que ainda existem outras questões tais como preço, tamanho, estilo, modelagem, acessibilidade que são preponderantes no momento da escolha. Essas questões acabam por sobrepor a busca por informações e ações de combate às más condições de trabalho.

Tais fatos reforçam que, embora existam movimentos slow fashion e de mecanismos de informação sobre as práticas empresariais como o Movimento Fashion Revolution e aplicativos como o Moda Livre, sua efetivação no processo decisório de compra ainda é incipiente. Isso pode se dar por limitações da comunicação dos próprios movimentos que não se fazem chegar em todos os públicos, 
ou mesmo pela abordagem adotada nas mensagens que não tem causado tanto impacto na busca por esse tipo de informação.

Do ponto de vista gerencial, aumentar a transparência das empresas em relação ao processo produtivo, também pode representar um diferencial mercadológico no sentido de ampliar o espectro de significados para o consumidor de que o produto não só tem atributos utilitários e/ou hedônicos, mas também tem um papel social de combate ao trabalho alusivo ao escravo. 0 investimento na divulgação desses aspectos em campanhas publicitárias poderia incitar o consumidor a pesquisar e se interessar mais por conhecer o processo produtivo e, assim, valorizar as empresas que são responsáveis quanto aos seus funcionários de produção.

Como contribuição acadêmica, esse estudo amplia a discussão do estudo do comportamento do consumidor sob a perspectiva do papel social do consumo em relação às condições de trabalho no processo produtivo de moda, destacando que o consumidor tem como prioridades no processo de decisão de compra de roupas aspectos individuais em detrimento de uma análise mais ampla que abarque questões sociais. Apresenta-se como limitação do trabalho o perfil heterogêneo das respondentes, sendo este não recomendado por uma corrente de autores, porém foi escolhido propositalmente, por se ter a intenção de gerar discussões a partir de diferentes pontos de vista. Em pesquisas futuras, sugere-se avaliar como as empresas do segmento tratam do assunto e se têm ferramentas de transparência disponíveis ao consumidor, além disso pode-se também observar se esse comportamento também se repete em questões relativas à sustentabilidade ambiental.

\section{Referências}

Abreu, N. R. D., Baldanza, R. F., \& Gondim, S. M. G. (2009). Os grupos focais on-line: das reflexões conceituais à aplicação em ambiente virtual. JISTEM-Journal of Information Systems and Technology Management, 6(1), 5-24.

Balduíno, D. T. (1999) (Org.). Trabalho escravo no Brasil contemporâneo. Edições Loyola. São Paulo, Brasil.

Barnes, L., Lea-Greenwood, G., Watson, M. Z., \& Yan, R. N. (2013). An exploratory study of the decision processes of fast versus slow fashion consumers. Journal of Fashion Marketing and Management: An International Journal, 17(2), 141-159

Baudrillard, J. (1998). The consumer society - Myths and Structures. London, Editora Sage.

Baumam, Z. (2008). Vida para o consumo. Rio de Janeiro: Zahar.

Bauman, Z. (2008.) A ética é possível num mundo de consumidores? Rio de Janeiro: Zahar.

Belk, R. W. (2013). Extended self in a digital world. Journal of consumer research, 40(3), 477-500.

Brasil, Repórter. (2015) Trabalho escravo contemporâneo - 20 anos de combate [1995-2015]. São Paulo.

Cairns, G., \& Roberts, J. (2007). A discussion of Fashion Victims. Critical perspectives on international business, 3(2), 170-185.

Choi, T. M., Lo, C. K., Wong, C. W., Yee, R. W., \& Chan, T. Y. (2012). The consumption side of sustainable fashion supply chain. Journal of Fashion Marketing and Management: An International Journal, 16(2), 193-215.

Churchill Jr, G. A. (1979). A paradigm for developing better measures of marketing constructs. Journal of marketing research, 16(1), 64-73.

Cline, E. L. O. (2012). The Shockingly high cost of cheap fashion. New York: Portfolio.

Close, P. (2014) Child labour in global society. Emerald Group Publishing.

Clube, R. K., \& Tennant, M. (2020). Exploring garment rental as a sustainable business model in the fashion industry: Does contamination impact the consumption experience? Journal of Consumer Behaviour, 19(4), 359-370.

Cietta, E. (2010). A revolução do fast-fashion: estratégias e modelos organizativos para competir nas indústrias híbridas. São Paulo: Estação das Letras e Cores, 1. 
Cordeiro, A. T., Batista, M. D. M., Silva, M. A. P. D., \& Pereira, G. D. F. (2013). Consumidora consciente?! Paradoxos do discurso do consumo sustentável de moda. Revista Brasileira de Marketing, 12(3), 01-22.

Dantas, B. L. L. (2018). " Look do dia": consumo conspícuo de fast fashion e construções identitárias no Instagram. (Dissertação de mestrado). Disponível em: https://repositorio.ufpb.br/jspui/bitstream/123456789/12947/1/Arquivototal.pdf

Menezes, U. G. (2018). Consumo colaborativo: um caminho para o desenvolvimento sustentável? Consumer Behavior Review, 2(Special Edition), 56-68.

Evans, S., \& Peirson-Smith, A. (2018). The sustainability word challenge: Exploring consumer interpretations of frequently used words to promote sustainable fashion brand behaviors and imagery. Journal of Fashion Marketing and Management, 22(2), 252-269.

Farias, M. L., de Sousa Júnior, J. H., Silva, B. G. F., \& Alcoforado, D. G. (2019). Compreendendo o domínio "projetos de identidade do consumidor": Revisão de literatura considerando a produção científica brasileira. Consumer Behavior Review, 3(2), 85-98.

Fashion Revolution Brazil. (n.d.). Disponível em: https://www.fashionrevolution.org/southamerica/brazil/. Acesso em 03 de agosto de 2020.

Fletcher, K. (2010). Slow fashion: An invitation for systems change. Fashion Practice, 2(2), 259-265.

Fletcher, K. (2007). THE GREEN PAGES-Slow fashion-It's quality not quantity that counts, says eco textile designer Kate Fletcher. Ecologist, 37(5), 71-71.

Fletcher, K. (2008). Sustainable fashion and textiles: design journeys, Earthscan. London, Sterling.

Global Slavery Index. (2014). Disponível em: https://reporterbrasil.org.br/wpcontent/uploads/2014/11/GlobalSlavery 2014 LR-FINAL.pdf. Acesso em 26 abril 2020.

Jørgensen, M. S., \& Jensen, C. L. (2012). The shaping of environmental impacts from Danish production and consumption of clothing. Ecological Economics, 83, 164-173.

Jung, S., \& Jin, B. (2016). From quantity to quality: Understanding slow fashion consumers for sustainability and consumer education. International journal of consumer studies, 40(4), 410421.

Kim, H., Choo, H. J., \& Yoon, N. (2013). The motivational drivers of fast fashion avoidance. Journal of Fashion Marketing and Management, 17(2), 243-260.

Lai, S. M., \& Prendergast, G. (2019). How men interpret women's luxury brand signals. Journal of Fashion Marketing and Management: An International Journal, 23(2), 209-223.

Lipovetsky, G. (2007). A felicidade paradoxal: ensaio sobre a sociedade de hiperconsumo. São Paulo: Companhia das Letras.

Lipovetsky, G. (2009). O império do efêmero: a moda e seu destino nas sociedades modernas. Editora Companhia das Letras.

Lüdke, M., \& André, M. (1986). Pesquisa em educação: abordagens qualitativas. E.P.U.

Mahoney, M. (2018). The latest fashion trend: water sustainability and social ethics (Tese de doutorado). Disponível em: https://dspace.sunyconnect.suny.edu/handle/1951/70314.

Mano, R. F. (2014). Consumidor com deficiência: implicações de fatores pessoais e contextuais no consumo em redes varejistas de João Pessoa-PB. (Dissertação de mestrado). Disponível em: https://repositorio.ufpb.br/jspui/handle/tede/3866

Merriam, S. B., \& Tisdell, E. J. (2015). Qualitative research: A guide to design and implementation. John Wiley \& Sons.

McCracken, G. (2003). Cultura \& Consumo. Mauad Editora Ltda.

McCracken, G. (2007). Cultura e consumo: uma explicação teórica da estrutura e do movimento do significado cultural dos bens de consumo. Revista de Administração de Empresas, 47(1), 99-115.

McNeill, L., \& Moore, R. (2015). Sustainable fashion consumption and the fast fashion conundrum: fashionable consumers and attitudes to sustainability in clothing choice. International Journal of Consumer Studies, 39(3), 212-222.

McNeill, L. S., \& Snowdon, J. (2019). Slow fashion-Balancing the conscious retail model within the fashion marketplace. Australasian Marketing Journal (AMJ), 27(4), 215-223.

Morgan, D. L. (1996) Focus groups. Annual Review of Sociology, 22(1), 129-152. 
Nascimento, T. M. (2019). Examinando o Domínio do Comportamento Pró-ambiental na Promoção do Bem-estar Individual e Coletivo. CBR-Consumer Behavior Review, 3(1), 27-41.

Neto, V. P. (2008). Conceito jurídico e combate ao trabalho escravo contemporâneo. LTR: São Paulo.

Nunes, M. P., \& da Silveira, G. A. (2016). Análise das motivações do consumidor de fast-fashion. Revista de Administração IMED, 6(1), 56-71.

Organização Internacional do Trabalho. Convenção (29) sobre o trabalho forçado ou obrigatório. (1930). Disponível em: http://www.oit.org.br/sites/all /forced labour/oit/convencoes/conv 29.pdf. Acesso em: 27 de abril de 2020.

ONU Brasil. Assembléia Ambiental da ONU mira soluções inovadoras para o futuro global.https://nacoesunidas.org/assembleia-ambiental-da-onu-mira-solucoes-inovadoras-parafuturo-global/. Acesso em: 08 de agosto de 2020

Orlandi, E. P. (2009). Análise de discurso: princípios e procedimentos. 8a Edição, Campinas, SP: Pontes.

Ozdamar Ertekin, Z., \& Atik, D. (2015). Sustainable markets: Motivating factors, barriers, and remedies for mobilization of slow fashion. Journal of Macromarketing, 35(1), 53-69.

Pereira, G. R., Veiga, A. R., Oliveira Júnior, J. C. \& Oliveira, H. C. (2017). Marketing verde: Fatores da geração Z sobre questões ambientais. Consumer Behavior Review, 1(2), 58-72.

Papaoikonomou, E., \& Alarcón, A. (2017). Revisiting consumer empowerment: An exploration of ethical consumption communities. Journal of Macromarketing, 37(1), 40-56.

Pookulangara, S., \& Shephard, A. (2013). Slow fashion movement: Understanding consumer perceptions-An exploratory study. Journal of Retailing and Consumer Services, 20(2), 200-206.

Revolution, F. (2016). Fashion Transparency Index.

Roussenq, D. (2017). Internacionalização da produção vestuarista e a questão do trabalho: estudo de caso sobre a rede fast fashion Zara pela ótica das cadeias de valor globais. Disponível em: https://repositorio.ufsc.br/bitstream/handle/123456789/184982/Monografia\%20da\%20Day ana.pdf?sequence $=1$ \&isAllowed $=y$

Schiavini, J. M., \& Garrido, I. (2018). Análise de Conteúdo, Discurso ou Conversa? Similaridades e Diferenças entre os Métodos de Análise Qualitativa. Revista ADM. MADE, 22(2), 01-12.

Solér, C., Baeza, J., \& Svärd, C. (2015). Construction of silence on issues of sustainability through branding in the fashion market. Journal of Marketing Management, 31(1-2), 219-246.

Stake, R. E. (2011). Pesquisa Qualitativa: estudando como as coisas funcionam. Porto Alegre: Artmed.

Watson, M. Z., \& Yan, R. N. (2013). An exploratory study of the decision processes of fast versus slow fashion consumers. Journal of Fashion Marketing and Management: An International Journal United Kingdom, 7(2), 141-159.

Zanette, M. C., Lourenço, C. E., \& Brito, E. P. Z. (2013). o peso do varejo, o peso no varejo e a identidade: uma análise de consumidoras plus size. Revista de Administração de Empresas, 53(6), 539-550. 